\section{Oral Health-Related Quality of Life and Associated Factors in Brazilian Adolescents}

Paulo Roberto Grafitti Colussi', Fernando Neves Hugo², Francisco Wilker

Mustafa Gomes Muniz ${ }^{3}$, Cassiano Kuchenbecker Rösing ${ }^{3}$

This study aimed to assess the impact of oral health on the quality of life of adolescents. A cross-sectional study was performed with students from public and private schools from Passo Fundo, Brazil. All students were aged between 15 and 19 years old. The proportional random sample consisted of 736 adolescents from 20 schools. A structured questionnaire was applied, and an oral examination was performed, counting the number of teeth. Oral health-related quality of life was assessed by OHIP-14. Associations between quality of life and associated factors were analyzed. The mean OHIP-14 score was 7.25. Age, ethnicity and studying in a public school were associated to the OHIP-14 score. Tooth loss $(p=0.79)$ was not associated with quality of life. Additionally, questions related to appearance, such as whether teeth appearance bothers the adolescent $(p=0.68)$ were not associated with quality of life. Attending a public school (OR=1.63; Cl95\%:0.98-2.70) and self-reported halitosis (OR=1.48; $\mathrm{Cl} 95 \%$ : 1.01-2.16) were strongly associated to higher impact on quality of life. It was concluded that socioeconomic conditions and halitosis were associated to higher impact on quality of life of adolescents

\author{
'Department of Periodontology. \\ UPF - Universidade de Passo \\ Fundo, Passo Fundo, RS, Brazil \\ ${ }^{2}$ Department of Community Dentistry, \\ UFRGS - Universidade Federal do Rio \\ Grande do Sul, Porto Alegre, RS, Brazil \\ ${ }^{3}$ Department of Periodontology. \\ UFRGS - Universidade Federal do Rio \\ Grande do Sul, Porto Alegre, RS, Brazil
}

Correspondence: Cassiano

Kuchenbecker Rösing, Ramiro

Barcelos, 2492. 90035-003 Porto

Alegre, RS, Brasil. Tel: +55-51-3308-

5318. e-mail: ckrosing@hotmail.com

Key Words: quality of life, observational study, adolescence, oral health, mouth diseases.

\section{Introduction}

The impact of diseases and their treatment on quality of life received increasing importance. It should be considered when assessing health conditions and treatment results $(1,2)$. Therefore, assessing the psychosocial consequences of diseases is as important as assessing the presence of diseases.

Oral health-related quality of life concerns with the way oral diseases disturb the regular functioning of an individual, and it is an important focus for assessing the impact of oral conditions on adults and children $(3,4)$. A short version of the Oral Health Impact Profile comprising 14 items (OHIP-14) has been validated in Brazil and is useful to assess oral health related quality of life (5).

Few studies have assessed the relation between tooth loss and its impact on quality of life in adolescents. Generally, oral health outcomes seem not to be strongly associated to the decrease in quality of life in this age. Biazevic et al. (6) reported a mean OHIP-14 of 3.95 in a city in southern Brazil. The two most prevalent chronic oral diseases are caries and periodontal disease, which do not often present symptoms in early stages and hence do not seem to be strongly associated with higher impacts in quality of life in adolescents (1). Another aspect rarely addressed in adolescence is the impact of true outcomes on quality of life, such as oral health self-perception, tooth loss and questions involving esthetics and appearance.

Usually, studies demonstrate that tooth loss has an impact on quality of life in adults and elderly $(1,7-10)$, indicating that the amount of lost teeth increases the impact. When observing that the average tooth loss is decreasing in adolescents $(11,12)$, the question whether one or two lost teeth are important in this stage of life remains unanswered. Moreover, teeth lost in adolescence are usually molars $(11,13)$, which do not interfere in appearance.

Nonetheless, when analyzing the results from adolescents who reported higher impact on quality of life, the impacts most reported were difficulty to eat and smile, and even the presence of moderate pain $(6,14)$. This demonstrates that despite the low impact of oral health on the quality of life of adolescents, it is already noticed usually in those who present worse oral health conditions.

Another aspect poorly addressed in adolescence is halitosis. This is a highly prevalent problem in the general population (15) and it is important because any situation that would either embarrass or inhibit the adolescents may interfere in their social development. Astudy on adolescents showed that those with self-reported halitosis had lower scores of quality of life measured by the OHIP-14 (16).

The null hypothesis of this study is that there are no statistically significant differences in the oral health-related quality of life in adolescents regarding gender, ethnicity, mother's level of education, type of school, exposure to smoking, health problems, tooth brushing frequency, use of dental floss, tooth loss, self-reported halitosis, and concerning with oral health in general. Therefore, this study 
aimed to assess the impact of oral health on quality of life among high school adolescent students from a mediumsized city in southern Brazil.

\section{Material and Methods}

\section{Study Design and Location}

This cross-sectional study involved adolescents aged from 15 to 19 years old from both public and private high schools in the city of Passo Fundo, Brazil. In 2012, the city had 7,558 students enrolled in regular high school in 23 schools, 16 of them public $(6,256$ students, $82.78 \%)$ and 7 private schools (1,302 students, 17.22\%) (17).

\section{Ethical Considerations}

The Institutional Review Board of the University of Passo Fundo approved the present study following the authorization by the $7^{\text {th }}$ Regional Office of Education to carry out the study in public schools and after formal approval by the principals of the private schools. All selected students presented the Informed Consent Form signed by the parents or legal caretaker person and those that were at school in the day of the survey were interviewed and examined.

\section{Sample and Power Calculation}

All high schools were invited by the coordinator to participate and 20 of them accepted the invitation. Thirty percent of high school students from each school were invited to participate. The students were randomly chosen by draw from the lists of all high school students aged 15 to 19 years from each participating school.

The research team visited all classrooms that had selected students to present the study objectives. After the explanation, the chosen students received the Informed Consent Form to be signed by their responsible persons. In case of absence, a later contact was made.

The following parameters were used to estimate study power: alpha of $5 \%$, power of 0.80 , with a prevalence of self-reported halitosis of 35.9\% in the lowest and $44.9 \%$ in the upper tertiles of OHIP-14. A required sample size of 752 participants, which is closer of the final sample of 736 participants, would be required in order to provide a sample power of 0.05 . The explanation of the way power calculation was performed is: data indicated that the probability of halitosis among participants with better quality of life is $35 \%$. If the true probability of exposure among participants with worse quality of life is $44 \%$, we will be able to reject the null hypothesis that the exposure rates for participants with better or worse quality of life are equal with probability (power) of 0.05 if the study has 730 subjects, as the present one (in fact, 736 subjects). The Type I error probability associated with this test of this null hypothesis is 0.05 .

\section{Clinical Examination and Interview}

A structured questionnaire including demographic data, socioeconomic condition, general health behavior, health record and oral health self-perception was applied by a group of questions from the PCATool-SB Brazil adult version, validated for Brazil. Questions regarding teeth appearance were obtained from a validated questionnaire (18). Information about oral hygiene habits and halitosis were included. Halitosis was assessed by the question: "Do you have bad breath?" and answered with a Likert scale response card. The validated Brazilian version of the OHIP14 instrument (5) was used to assess quality of life. The answers to each question were obtained by choosing one option in the Likert scale (never $=0$ point, rarely $=1$ point, sometimes $=2$ points, often $=3$ points and al ways $=4$ points). The questionnaire was applied in duplicate with a one-week interval between the applications to 10 non-participants, with perfect agreement in this subject.

Except for the third molar, all teeth were counted after the interview with the help of a wooden spatula. Teeth that could somehow be restored were considered in the counting. Teeth or roots requiring extraction were not counted.

The adolescents were examined and interviewed between April and July 2012 by trained teams, composed by five dental students and checked by the study coordinator. The training consisted of theoretical lectures on the subject, as well as reading and explanation of each question from the questionnaire. The training was performed with the research members, after that, with the high school students who were not chosen to participate in the study, and included duplicate assessment by the study coordinator. Clinical examination reproducibility was verified in $10 \%$ of the examinees chosen by draw, revealing an agreement rate of 98\% (kappa=0.96), considered a proper reproducibility.

\section{Statistical Analysis}

The dependent variable of the present study was quality of life assessed by OHIP-14, divided into tertiles. Tertile 1 with lowest OHIP scores, tertile 2 with intermediate scores, tertile 3 with highest scores. The explanatory variables for the quality of life outcome in adolescents were divided into three groups (Fig. 1).

Ethnicity/skin color was classified either as white or non-white. The socioeconomic condition was assessed by a series of information on income and education. The mother's level of education was classified in three groups -complete or incomplete higher education; complete or incomplete high school and those who finished elementary school at most. Public or private school was used as income 


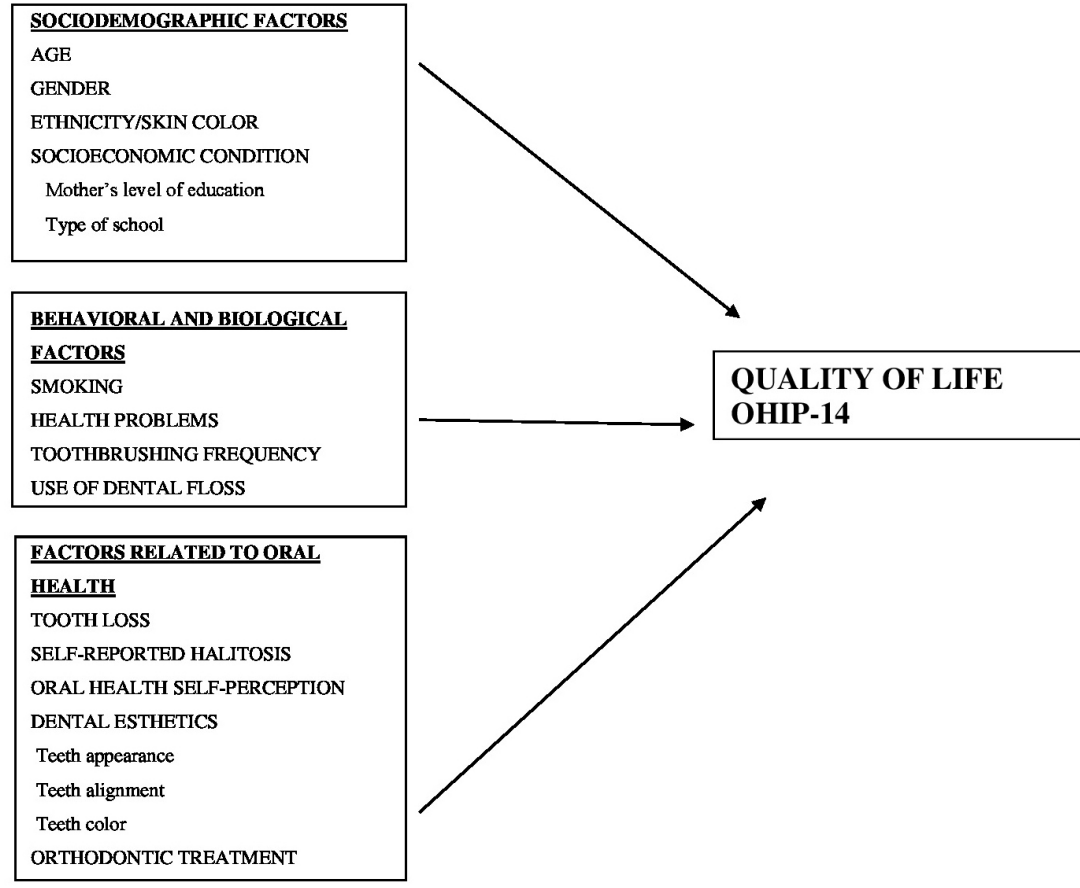

Figure 1. Explanatory variables for Quality of life (OHIP-14).

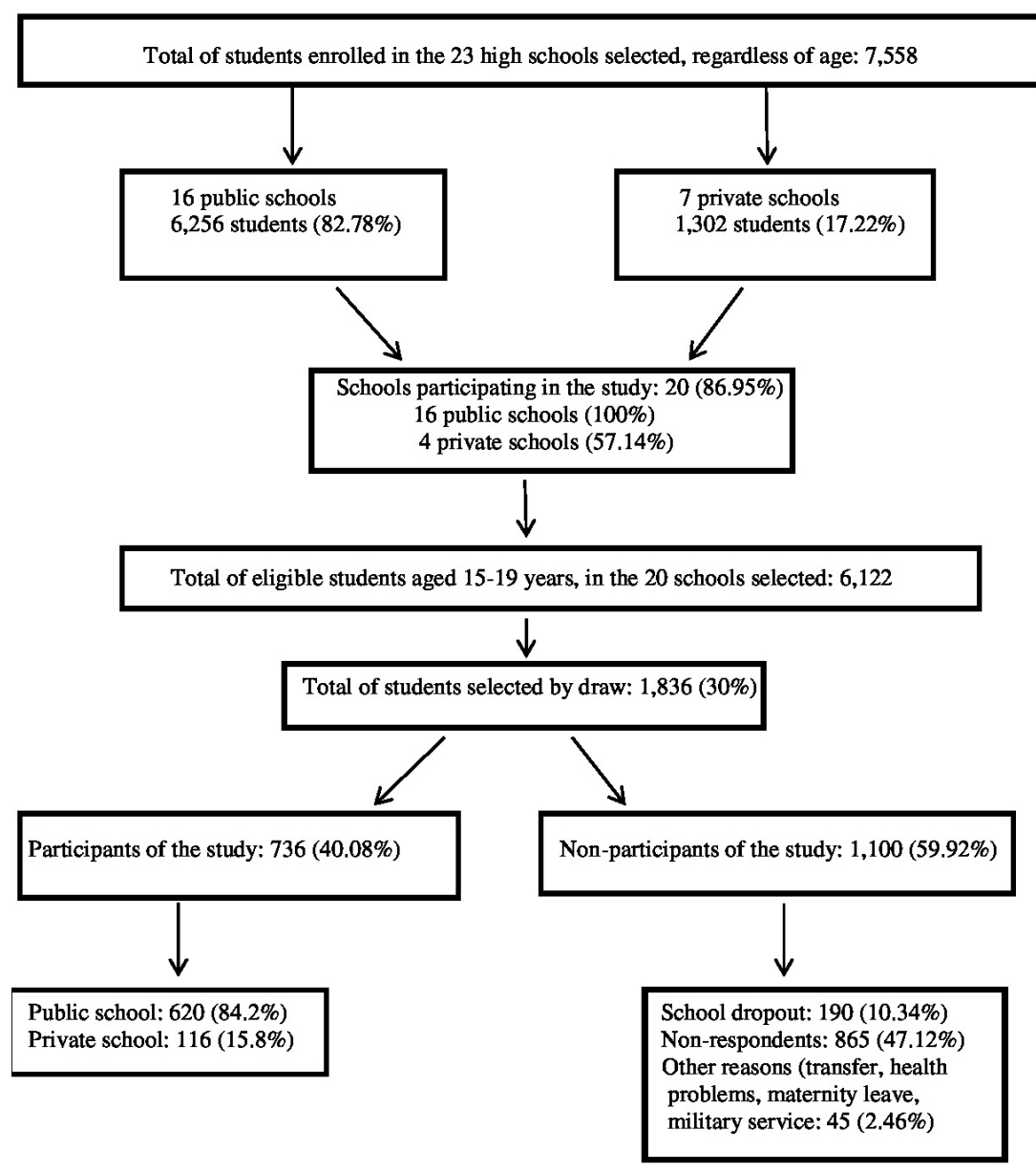

Figure 2. Flowchart of the study. proxy, as students from public schools are considered to come from lower income families.

Smoking was classified in two groups - those without any smoking exposure, and current or former smokers. Health problem was classified in two groups those without a health problem or not aware of it and those who reported a health problem that lasted or will probably last more than one year. Self-reported tooth brushing frequency was classified in three groups -more than three times/day, three times/day and less than three times/day. The use of dental floss, tooth loss and those under orthodontic treatment were dichotomized into yes or no.

Self-reported halitosis was classified in yes for those who answered sometimes, often and always; and no for those who answered never and rarely. Oral health self-perception was dichotomized into yes or no for those who were concerned or not with their oral health, respectively. Questions regarding dental esthetics were addressed by three questions: whether teeth appearance bothers the adolescent, whether teeth alignment is a concern, and whether teeth color is a concern.

Data analysis was performed using the statistical package SPSS 18 (SPSS Inc., Chicago, IL, USA). Associations between the dependent variable and independent variables were analyzed by chi-square or Fisher's exact tests and presented by frequency distribution. Uni- and multivariate multinomial regression models were used to assess the association between dependent and independent variables. The covariates were chosen based on either association in univariate analysis $(p<0.20)$ or from conceptual basis. Figure 1 exhibits all included variables. The applied significance 
level was $5 \%$.

\section{Results}

Among the 6,122 students eligible for the study in the 20 selected schools, 1,836 students were chosen by draw and invited to participate in the study, 736 accepted the invitation (participation rate: $40.08 \%$ ). Among them, 323 (43.9\%) were male, and 413 (56.1\%) female. Reasons for non-participation and the number of subjects in both private and public schools are shown in Figure 2. The prevalence of at least 1 lost tooth was $21.1 \%$ with a 0.42 mean of lost teeth. Mean OHIP-14 was 7.25 \pm 6.78 .

Age, ethnicity, type of school and self-reported halitosis did not present statistically significant association with the OHIP-14 score, although they presented p-values lower than the limits for inclusion in posterior models (Table 1). Tooth loss and questions related to appearance were not associated to impact on quality of life. When the univariate model was analyzed (Table 2), adolescents from public schools and with self-reported halitosis presented higher association to quality of life outcome. Adolescents with halitosis had 1.45 times higher chances to be in the third tertile of the OHIP-14 score. Adolescents from
When the multivariate model was analyzed (Table 3), statistically significant associations between the type of school and self-reported halitosis were obtained. Adolescents from public schools had 63\% higher chances to be in the third tertile of the OHIP-14 score. Likewise, adolescents who claimed to have halitosis had 1.48 times higher chances to be in the third tertile.

\section{Discussion}

The present study evaluated the impact of factors related to oral health on quality of life among adolescents. Additionally was assessed the impact of halitosis in the quality of life of adolescents. The influence of sociodemographic and behavioral factors on quality of life was also assessed. It was shown that age, ethnicity and studying in a public school were associated to the OHIP-14. Furthermore, in the multivariate analysis, it was shown that attending a public school and self-reported halitosis were significantly associated with higher impact on quality of life. On the other hand, tooth loss and teeth appearance were not significantly associated with oral health-related quality of life.

The study sought to represent high school students from the city of Passo Fundo, RS, Brazil. Every school of the city was invited and 23 agreed to participate. Within each school, a simple random sample of individuals of the involved age group was selected, and the response rate was $40.08 \%$. In this sense, studies with higher $(19)$, similar $(8,20)$ and lower response rates compared with the present study are found in the literature (21). The response rate in the present study may represent its own limitation. However, the difficulties associated with the age group, including the logistics of signing the Informed Consent Form by the responsible persons, may account for the attrition.

Thirty percent of students from each school were invited to in order not to oversample any school. A census would not be possible and other studies in this field have used smaller sample size when compared to this study $(22,23)$. The a posteriori power calculation showed that the sample size of the study is close to the one required for a power of 0.80 . Other studies have used similar size samples $(24,25)$.

In Brazil, there are adolescents out of school and with significant school delay, who might not have reached high school. Thus, we cannot imply representation for all adolescents. Nonetheless, the rate of participants and the sociodemographic variables, such as gender and ethnicity, of this study were similar to the city rates. Therefore, this study represents only high school adolescents.

Efforts were made to decrease the study biases, especially regarding measurements. The OHIP-14 instrument was thoroughly explained and all doubts were settled by the study coordinator. It is important to highlight that the OHIP-14 was built and validated in Brazil, and it is a proper instrument to assess oral health-related quality (5).

The authors divided the sample using tertiles for the OHIP-14. This is an arbitrary approach that was used in another study (26). The idea behind this model is to distinguish between different result patterns in the study population. In epidemiology is reasonably common to use cut-off points based on data distribution.

These results infer a relatively higher impact on quality of life when compared to some published studies among adolescents $(6,27)$. However, similar means of OHIP-14 have also been reported in the literature. A study with Brazilian male incarcerated adolescents showed a mean OHIP-14 score of $6.69 \pm 8.79$ (28) and an Iranian group of adolescents with untreated moderate malocclusion had a mean OHIP-14 score of $8.25 \pm 3.88$ (29). These are specific samples with possibly greater impact in the quality of life. In the present study, a mean OHIP-14 of 7.25 could relate to halitosis.

Most adolescents considered their oral health as good, possibly explaining the low scores showed in these studies. Furthermore, negative impact of quality of life measured by the OHIP-14 is usually increased by higher DMFT (30). 
Tooth loss, oral health self-perception, and questions related to appearance and esthetics were not associated to OHIP-14 scores in this study. The two most prevalent chronic oral diseases - dental caries and periodontal disease - do not seem strongly associated to the decrease in oral health-related quality of life in adolescents (1). This

Table 1. Frequency distribution of exposures regarding prevalence of impact on quality of life among adolescents from 15 to 19 years old, Passo Fundo, RS, Brazil 2012

\begin{tabular}{|c|c|c|c|c|c|}
\hline & & $\begin{array}{c}\text { Tertile } 1 \\
\mathrm{~N}=225\end{array}$ & $\begin{array}{c}\text { Tertile } 2 \\
\mathrm{~N}=277\end{array}$ & $\begin{array}{c}\text { Tertile } 3 \\
\mathrm{~N}=234\end{array}$ & p-value \\
\hline \multirow{2}{*}{ Gender } & Male & $98(43.6 \%)$ & $122(44.0 \%)$ & $103(44.0 \%)$ & 0.99\# \\
\hline & Female & $127(56.4 \%)$ & $155(56.0 \%)$ & $131(56.0 \%)$ & \\
\hline \multirow{2}{*}{ Ethnicity } & White & $148(65.8 \%)$ & $206(74.4 \%)$ & $157(67.1 \%)$ & $0.07 \#$ \\
\hline & Non-white & $77(34.2 \%)$ & $71(25.6 \%)$ & $77(32.9 \%)$ & \\
\hline \multirow{3}{*}{ Mother's level of education } & Complete or incomplete higher education & 57 (25.3\%) & $60(21.7 \%)$ & $47(20.1 \%)$ & $0.66 \#$ \\
\hline & Complete or incomplete high school & $75(33.3 \%)$ & $100(36.1 \%)$ & $90(38.5 \%)$ & \\
\hline & Finished up to elementary school & $93(41.4 \%)$ & $117(42.2 \%)$ & $97(41.4 \%)$ & \\
\hline \multirow{2}{*}{ Type of school } & Public & $181(80.4 \%)$ & $236(85.2 \%)$ & $203(86.8 \%)$ & $0.15 \#$ \\
\hline & Private & $44(19.6 \%)$ & $41(14.8 \%)$ & $31(13.2 \%)$ & \\
\hline \multirow{2}{*}{ Smoking } & Never smoked & $212(94.2 \%)$ & $262(94.6 \%)$ & $219(93.6 \%)$ & $0.89^{*}$ \\
\hline & Smoker or former smoker & $13(5.8 \%)$ & $15(5.4 \%)$ & $15(6.4 \%)$ & \\
\hline \multirow{2}{*}{ Health problems } & Yes & $24(10.7 \%)$ & $36(13.3 \%)$ & $31(13.4 \%)$ & $0.61 \#$ \\
\hline & No & $200(89 \%)$ & $235(86.7 \%)$ & $200(86.6 \%)$ & \\
\hline \multirow{3}{*}{ Toothbrushing frequency } & $>3 x$ a day & $67(29.8 \%)$ & $68(24.5 \%)$ & $51(21.8 \%)$ & $0.28 \#$ \\
\hline & $3 x$ a day & $123(54.7 \%)$ & $170(61.4 \%)$ & $142(60.7 \%)$ & \\
\hline & $<3 x$ a day & $35(15.5 \%)$ & $39(14.1 \%)$ & $41(17.5 \%)$ & \\
\hline \multirow{2}{*}{ Use of dental floss } & Yes & $121(53.8 \%)$ & $151(54.5 \%)$ & $118(50.4 \%)$ & $0.62 \#$ \\
\hline & No & $104(46.2 \%)$ & $126(45.5 \%)$ & $116(49.6 \%)$ & \\
\hline \multirow{2}{*}{ Tooth loss } & Yes & $50(22.2 \%)$ & $59(21.3 \%)$ & $46(19.7 \%)$ & $0.79 \#$ \\
\hline & No & $175(77.8 \%)$ & $218(78.7 \%)$ & $188(80.3 \%)$ & \\
\hline \multirow{2}{*}{ Self-reported halitosis } & Yes & $101(44.9 \%)$ & $107(38.6 \%)$ & $84(35.9 \%)$ & $0.13 \#$ \\
\hline & No & $124(55.1 \%)$ & $170(61.4 \%)$ & $150(64.1 \%)$ & \\
\hline \multirow{2}{*}{ Concerns with oral health } & Yes & $114(50.7 \%)$ & $154(55.6 \%)$ & $121(51.7 \%)$ & $0.49 \#$ \\
\hline & No & $111(50.7 \%)$ & $123(44.4 \%)$ & $113(48.3 \%)$ & \\
\hline \multirow{2}{*}{ Bothering teeth appearance } & Yes & $126(56.0 \%)$ & $163(58.8 \%)$ & $140(59.8 \%)$ & $0.68 \#$ \\
\hline & No & $99(44.0 \%)$ & $114(41.2 \%)$ & $94(40.2 \%)$ & \\
\hline \multirow{2}{*}{ Concerns with teeth alignment } & Yes & $94(41.8 \%)$ & $117(42.2 \%)$ & $112(47.9 \%)$ & $0.33 \#$ \\
\hline & No & $131(58.2 \%)$ & $160(57.8 \%)$ & $122(52.1 \%)$ & \\
\hline \multirow{2}{*}{ Concerns with teeth color } & Yes & $124(55.1 \%)$ & $157(56.7 \%)$ & $126(53.8 \%)$ & $0.81 \#$ \\
\hline & No & $101(44.9 \%)$ & $120(43.3 \%)$ & $108(46.2 \%)$ & \\
\hline \multirow{2}{*}{ Orthodontic treatment } & Yes & $134(59.6 \%)$ & $151(54.5 \%)$ & $139(59.4 \%)$ & $0.42 \#$ \\
\hline & No & $91(40.4 \%)$ & $126(45.5 \%)$ & $95(40.6 \%)$ & \\
\hline
\end{tabular}


seems to happen with tooth loss as well. Regarding tooth loss in adolescents the few studies with representative samples discussing the subject in adolescents (11), hinder comparisons. Additionally, most studies addressing tooth

loss in adolescents do not include the assessment of its impact on quality of life.

Most studies assessing

Table 2. Univariate analysis model associating exposures regarding prevalence of impact on quality of life among adolescents from 15 to 19 years old, Passo Fundo, RS, Brazil 2012

\begin{tabular}{|c|c|c|c|c|c|}
\hline & & Tertile 2 & & Tertile 3 & \\
\hline & & OR (CI 95\%) & & OR (CI 95\%) & \\
\hline Age & & $0.99(0.83-1.17)$ & 0.94 & $0.97(0.81-1.16)$ & 0.77 \\
\hline Gender & Male & $1.02(0.71-1.45)$ & 0.91 & $1.02(0.70-1.47)$ & 0.92 \\
\hline Ethnicity & Non-white & $1.51(1.02-2.21)$ & 0.36 & $1.06(0.72-1.56)$ & 0.76 \\
\hline \multirow[t]{3}{*}{$\begin{array}{l}\text { Mother's level } \\
\text { of education }\end{array}$} & Higher education & 1 (ref.) & & 1 (ref.) & \\
\hline & High school & $1.06(0.70-1.58)$ & 0.78 & $0.79(0.49-1.27)$ & 0.33 \\
\hline & $\begin{array}{l}\text { Illiterate to complete } \\
\text { elementary school }\end{array}$ & $0.83(0.53-1.31)$ & 0.44 & $1.15(0.75-1.75)$ & 0.51 \\
\hline Type of school & Public & $1.39(0.87-2.23)$ & 0.15 & $1.59(0.96-2.62)$ & 0.06 \\
\hline Smoking & Yes & $1.07(0.50-2.30)$ & 0.86 & $0.89(0.41-1.92)$ & 0.78 \\
\hline $\begin{array}{l}\text { Health } \\
\text { problems }\end{array}$ & Yes & $1.27(0.73-2.21)$ & 0.38 & $1.29(0.73-2.27)$ & 0.37 \\
\hline \multirow[t]{3}{*}{$\begin{array}{l}\text { Toothbrushing } \\
\text { frequency }\end{array}$} & $>3 x /$ day & 1 (ref.) & & 1 (ref.) & \\
\hline & $3 x /$ day & $0.91(0.51-1.60)$ & 0.74 & $1.24(0.74-2.07)$ & 0.41 \\
\hline & $<3 x /$ day & $0.65(0.36-1.16)$ & 0.14 & $0.96(0.59-1.64)$ & 0.95 \\
\hline $\begin{array}{l}\text { Use of dental } \\
\text { floss }\end{array}$ & No & $1.03(0.72-1.46)$ & 0.86 & $0.87(0.60-1.26)$ & 0.47 \\
\hline Tooth loss & Yes & $1.05(0.68-1.61)$ & 0.80 & $1.16(0.74-1.83)$ & 0.50 \\
\hline $\begin{array}{l}\text { Self-reported } \\
\text { halitosis }\end{array}$ & Yes & $1.29(0.90-1.84)$ & 0.15 & $1.45(1.00-2.11)$ & 0.05 \\
\hline $\begin{array}{l}\text { Concerns with } \\
\text { oral health }\end{array}$ & Yes & $1.21(0.85-1.73)$ & 0.27 & $1.04(0.72-1.50)$ & 0.82 \\
\hline $\begin{array}{l}\text { Bothering teeth } \\
\text { appearance }\end{array}$ & Yes & $1.12(0.78-1.60)$ & 0.52 & $1.17(0.80-1.69)$ & 0.40 \\
\hline $\begin{array}{l}\text { Concerns with } \\
\text { teeth alignment }\end{array}$ & Yes & $1.01(0.71-1.45)$ & 0.91 & $1.27(0.88-1.85)$ & 0.19 \\
\hline $\begin{array}{l}\text { Concerns with } \\
\text { teeth color }\end{array}$ & Yes & $1.06(0.74-1.51)$ & 0.72 & $0.95(0.65-1.37)$ & 0.78 \\
\hline $\begin{array}{l}\text { Orthodontic } \\
\text { treatment }\end{array}$ & Yes & $1.22(0.86-1.75)$ & 0.25 & $1.00(0.69-1.46)$ & 0.97 \\
\hline
\end{tabular}

Table 3. Multivariate analysis model associating exposures regarding prevalence of impact on quality of life among adolescents from 15 to 19 years old, Passo Fundo, RS, Brazil 2012

\begin{tabular}{|c|c|c|c|c|c|}
\hline & & Tertile 2 & \multirow[b]{2}{*}{ p-value } & Tertile 3 & \multirow{2}{*}{$\mathrm{p}$-value } \\
\hline & & OR (CI 95\%) & & $\begin{array}{l}\text { OR (CI } \\
95 \%)\end{array}$ & \\
\hline $\begin{array}{l}\text { Type of } \\
\text { school }\end{array}$ & Public & $\begin{array}{c}1.42 \\
(0.89-2.28)\end{array}$ & 0.13 & $\begin{array}{c}1.63 \\
(0.98-2.70)\end{array}$ & 0.05 \\
\hline $\begin{array}{l}\text { Self-reported } \\
\text { halitosis }\end{array}$ & Yes & $\begin{array}{c}1.31 \\
(0.91-1.87)\end{array}$ & 0.13 & $\begin{array}{c}1.48 \\
(1.01-2.16)\end{array}$ & 0.04 \\
\hline
\end{tabular}
tooth loss are performed in adult or elderly population, who present higher experience of tooth loss $(8,31)$. One systematic review showed that the lower the number of present teeth, the higher the impact on quality of life, especially when the number of remaining teeth in less than 20 (1). The results of the present study suggest that one or two lost teeth do not seem to interfere in the quality of life of adolescents. In this age, most of the lost teeth are posterior (11), explaining the low impact on quality of life. However, dental caries is the main cause of tooth loss in adolescents, which does not seem to have great importance for most of them. This may suggest that neither oral health affects quality of life, nor it is a priority in their lives.

The present study addressed specific questions on appearance and esthetics, including teeth appearance, teeth alignment and teeth color. However, none of the questions seem to have impacted the quality of life. Nonetheless, the difficulty to smile is already a problem in some studies with adolescents $(12,14)$, showing that this is a concern for this age group. Regarding this, it should be noted that many adolescents might feel embarrassed to admit problems with their appearance.

Adolescents from public schools were strongly associated with higher impact on quality of life. The type of school significantly contributed to the differences among adolescents regarding health risk behavior (32), and it may be a risk indicator for 
chronic oral diseases, especially concerning dental caries (33). In fact, adolescents from public schools present worse oral health conditions. The highest impacts on quality of life were noticed by public school students, although questions related to oral health were not associated in this study. These results suggest that adolescents from public schools perceive their oral health as being worse when compared to students from private schools. This may also be observed in a study with adolescents with apparent income differences. In another study, adolescents from lower income areas were more affected by dental caries and presented higher impact on quality of life (30).

Likewise, adolescents with self-reported halitosis had higher impact on quality of life. Halitosis is a health problem with high prevalence among all ages $(15,34)$. The social impact of halitosis is profound even for adolescents, harming social and professional life. Despite the importance of halitosis as a highly prevalent problem, few studies involving adolescents are available, including its impact on quality of life. Historically, halitosis was considered as a subject of minor importance in Dentistry, being managed many times by other professionals when it should have been mostly treated by dentists (15).

Some limitations related to this study should be highlighted. The inclusion of only adolescents attending to school limits the external validity of this study to all adolescents. The use of caries and periodontal diseases examination could bring more findings to this study. Furthermore, the response rate may be considered low; however, it is appropriate of this study design, as the parent's signature on the consent form may be accounted for this rate.

The results found in the present study are instigating and challenging. If on one hand the impacts of oral health in adolescence are relatively low, on the other hand it should be remembered that oral health problems are mostly cumulative. Surprisingly, tooth loss and questions related to appearance and esthetics were not associated to worse quality of life. However, public school students and halitosis were associated to higher impact on quality of life. Efforts towards specific health promotion for this life cycle including actions in every school, especially in public schools should be the focus of government health care policies.

\section{Resumo}

Esse estudo objetivou verificar o impacto da saúde bucal na qualidade de vida de adolescentes. Um estudo transversal foi realizado com estudantes de escolas públicas e privadas da cidade de Passo Fundo, Brasil. Todos os estudantes tinham idades entre 15 e 19 anos. Uma amostragem proporcional randômica consistiu em 736 adolescentes de 20 escolas. Um questionário estruturado foi aplicado e exames da cavidade oral foram realizados, contando-se o número de dentes presentes. Qualidade de vida associada à saúde bucal foi verificada pelo OHIP-14. Associações entre qualidade de vida e fatores associados foram analisadas. A média do OHIP-14 foi 7,25. Idade, etnia e estudar em escola pública estiveram associados com escores do OHIP-14. Perda dentária $(p=0,79)$ não esteve associada com qualidade de vida. Além disso, questões relacionadas com a aparência, como, por exemplo, se a aparência do dente incomoda o adolescente $(p=0,68)$, não estiveram associadas com qualidade de vida. Frequentar uma escola pública $(O R=1,63$; IC95\%: 0,98 - 2,70) e halitose autorreportada (OR=1,48; IC95\%: 1,01 - 2,16) estiveram fortemente associadas com altos impactos na qualidade de vida. Concluiu-se que condições socioeconômicas e halitose estão associadas com altos impactos na qualidade de vida de adolescentes.

\section{Acknowledgements}

This study was self-funded and all the authors report no conflict of interest.

\section{References}

1. Gerritsen AE, Allen PF, Witter DJ, Bronkhorst EM, Creugers NH. Tooth loss and oral health-related quality of life: a systematic review and meta-analysis. Health Qual Life Outcomes 2010;5:126-136.

2. Mendez M, Melchiors Angst PD, Stadler AF, Oppermann RV, Gomes S. Impacts of supragingival and subgingival periodontal treatments on oral health-related quality of life. Int J Dent Hyg 2017. [Epub ahead of print. doi: 10.1111/idh.12193].

3. Baker SR, Mat A, Robinson PG. What psychosocial factors influence adolescents' oral health? J Dent Res 2010;89:1230-1235.

4. Lu HX, Chen XL, Wong M, Zhu C, Ye W. Oral health impact of halitosis in Chinese adults. Int J Dent Hyg 2017. [Epub ahead of print. doi: 10.1111/ idh.12242]

5. Oliveira BH, Nadanovsky P. Psychometric properties of the Brazilian version of the Oral Health Impact Profile-short form. Community Dent Oral Epidemiol 2005;33:307-314.

6. Biazevic MG, Rissotto RR, Michel-Crosato E, Mendes LA, Mendes MO. Relationship between oral health and its impact on quality of life among adolescents. Braz Oral Res 2008;22:36-42.

7. Steele JG, Sanders AE, Slade GD, Allen PF, Lahti S, Nuttall N, et al.. How do age and tooth loss affect oral health impacts and quality of life? A study comparing two national samples. Community Dent Oral Epidemiol 2004;32:107-114.

8. Brennan DS, Spencer AJ, Roberts-Thomson KF. Tooth loss, chewing ability and quality of life. Qual Life Res 2008;17:227-235.

9. Sanders AE, Slade GD, Lim S, Reisine ST. Impact of oral disease on quality of life in the US and Australian populations. Community Dent Oral Epidemiol 2009;37:171-181.

10. Bortoluzzi MC, Traebert J, Lasta R, Da Rosa TN, Capella DL, Presta AA. Tooth loss, chewing ability and quality of life. Contemp Clin Dent 2012;3:393-397.

11. Susin C, Haas AN, Opermann RV, Albandar JM. Tooth loss in a young population from south Brazil. J Public Health Dent 2006;66:110-115.

12. Brasil. (2012). SB Brazil Project 2010, Brazilian Oral Health Survey, Maisn Results. Brasilia DF: Ministry of Health, 2012.

13. Barbato PR, Peres MA. Tooth loss and associated factors in adolescents: a Brazilian population-based oral health survey. Rev Saude Publica 2009;43:13-25.

14. Peres KG, Peres MA, Araujo CL, Menezes AM, Hallal PC. Social and dental status along the life course and oral health impacts in adolescents: a population-based birth cohort. Health Qual Life Outcomes 2009 doi:10.1186/1477-7525-7-95.

15. Rösing CK, Loesche W. Halitosis: an overview of epidemiology, etiology and clinical management. Braz Oral Res 2011;25:466-471.

16. Broughton JR, Teh Maipi J, Person M, Randall A, Thomson WM. Selfreported oral health and dental service-use of rangatahi within the rohe of Tainui. N Z Dent J 2012;108:90-94.

17. Passo Fundo. 7a Coordenadoria Regional de Educação - Passo Fundo Setor de Estatística, Passo Fundo, RS: Secretaria da Educação, 2011.

18. Furtado GE, Sousa ML, Barbosa TS, Wada RS, Martínez-Mier EA, Almeida ME. Percepção da fluorose dentária e avaliação da concordância 
entre pais e filhos: validação de um instrumento. Cad Saude Publica 2012;28:1493-1505.

19. Park YD, Patton LL, Kim HY. Clustering of oral and general health risk behaviors in Korean adolescents: a national representative sample. J Adolesc Health 2010;47:277-281.

20. Murray C, Densie IK, Morgan C. Dental attendance, perceptions of cost and self-care of school year 12 and 13 students: A focus on Southland, New Zealand. N Z Dent J 2015;111:133-141.

21. Skinner J, Johnson G, Phelan C, Blinkhorn A. Dental caries in 14- and 15 -year-olds in New South Wales, Australia. BMC Public Health Skinner J, Johnson G, Phelan C, Blinkhorn A. Dental caries in 14- and 15-yearolds in New South Wales, Australia. BMC Public Health. 2013;13:1060.

22. Javed $\mathrm{O}$, Bernabé E. Oral impacts on quality of life in adult patients with class I, II and III malocclusion. Oral Health Prev Dent 2016;14:27-32.

23. Almoznino G, Zini A, Aframian DJ, Kaufman E, Lvovsky A, Hadad A et al.. Oral health related quality of life in young individuals with dental anxiety and exaggerated gag reflex. Oral Health Prev Dent 2015;13:435-440.

24. Susin C, Haas AN, Valle PM, Oppermann RV, Albandar JM. Prevalence and risk indicators for chronic periodontitis in adolescents and young adults in south Brazil. J Clin Periodontol 2011;38:326-333.

25. Musskopf ML, Fiorini T, Haddad DC, Susin C. Tobacco use and smoking cessation among third-year dental students in southern Brazil. Int Dent J 2014;64:312-317.

26. Brennan DS, Spencer AJ. Life events and oral-health-related quality of life among young adults. Qual Life Res 2009;18:557-565.

27. Papaioannou W, Oulis CJ, Latsou D, Yfantopoulos J. Oral health related quality of life of Greek adolescents: a cross-sectional study. Eur Arch
Paediatr Dent 2011:12:146-150.

28. Oliveira DC, Ferreira FM, Morosini leA, Torres-Pereira CC, Martins Paiva $S$, Fraiz FC. Impact of oral health status on the oral health-related quality of life of Brazilian male incarcerated adolescents. Oral Health Prev Dent 2015;13:417-425.

29. Jamilian A, Kiaee B, Sanayei S, Khosravi S, Perillo L. Orthodontic treatment of malocclusion and its impact on oral health-related quality of life. Open Dent J 2016;10:236-241.

30. Bastos RS, Carvalho ES, Xavier A, Caldana ML, Bastos JR, Lauris JR. Dental caries related to quality of life in two Brazilian adolescent groups: a cross-sectional randomised study. Int Dent J 2012;62:137143.

31. De Marchi RJ, Hilgert JB, Hugo FN, Santos CM, Martins AB, Padilha DM. Four-year incidence and predictors of tooth loss among older adults in a southern Brazilian city. Community Dent Oral Epidemiol 2012;40:396-405.

32. Campus G, Cagetti MG, Senna A, Spano G, Benedicenti S, Sacco G. Differences in oral health among Italian adolescents related to the type of secondary school attended. Oral Health Prev Dent 2009;7:323-330.

33. Da Rosa P, Nicolau B, Brodeur JM, Benigeri M, Bedos C, Rousseau MC. Associations between school deprivation indices and oral health status. Community Dent Oral Epidemiol 2011;39:213-220.

34. Eldarrat $\mathrm{AH}$. Influence of oral health and lifestyle on oral malodour. Int Dent J 2011;61:47-51. 